\title{
Statistics of insect catch within historic properties
}

Peter Brimblecombe ${ }^{1 *}$, Caroline Truth Brimblecombe ${ }^{2}$, David Thickett ${ }^{3}$ and Dee Lauder ${ }^{4}$

\begin{abstract}
Introduction: Certain species of insect are known to cause damage to historic collections. For more than a decade insects have been identified in traps set out in English Heritage properties, the data from which has been used in this paper. Descriptive statistics have been used to explore the data structure and insect distribution.

Results: About 55\% of the traps of the more than 30000 traps examined over that period contained insects that were readily categorised. The rate of catch (insects/trap) was highest in London and the Southeast. Booklice (Liposcelis bostrychophila) and silverfish (Lepisma saccharina) were the most frequent catch. Woolly bear (Anthrenus spp.) larvae and crustacean woodlice (Porcellio spinicornis) were also common. A higher frequency of furniture beetles (Anobium punctatum) is notable in the Southeast and West. Despite this overall pattern, catch varied greatly between individual properties. The general view that insects have increased over time was not universal, although the dominant booklouse showed an increased catch over the last decade. The insects did not appear to be randomly distributed, but clustered onto traps in greater numbers than might be expected from a Poisson distribution, which suggested they occurred as infestations. Some insect species appeared in combination with other species at a higher frequency than expected, but the reasons for these associations were not always obvious. Pheromone traps collected more webbing and case bearing clothes moths (Tineola bisselliella, Tinea pellionella) than traps without attractants, much as expected. There are hints that covered traps may collect fewer insects than simple blunder traps.

Conclusions: No obvious drivers of high insect count were identified. Trends over time were not especially clear. The results provide clues to management of insect pests in historic properties. The presence and trapping of insects at a given property is individual in nature, and so mitigation strategies need to be site-specific. Although an insect might occur in low numbers in some periods, the possibility of infestation remains. Future work will examine the trends in catch more carefully and ascertain the importance of various environmental factors.
\end{abstract}

Keywords: Arthropods, Catch rate, English heritage stock, Environmental effects, Infestation, Insect distribution

\section{Introduction}

Insects have long been a problem because of the damage they can cause. In classical times there was discussion of the damage to clothes by moths, and of potential solutions to this nuisance. Insect pests attack furniture and textiles as well as the structure of wooden buildings, which is of great concern in historic properties. Properties that are no longer occupied offer insects an opportunity to occupy quiet habitats. Especially damaging to historic materials, are the larval stages of carpet beetle (Anthrenus spp.) and clothes moths (Lepidoptera: Tineidae), which feed on textiles, fur and leather, beetles

\footnotetext{
* Correspondence: P.Brimblecombe@uea.ac.uk

${ }^{1}$ School of Environmental Sciences, University of East Anglia, Norwich NR4 7TJ, UK

Full list of author information is available at the end of the article
}

that attack wood and furniture, and silverfish (Lepisma saccharina) and woodlice (Porcellio spp.) that damage books and wallpaper [1].

A general view has been expressed among some professionals in the heritage conservation field that there may be an increase in insect populations, with a move of more temperature-sensitive species northwards [2,3]. An example is the barkfly (order Psocoptera, which includes booklice) studied within the National Barkfly Recording Scheme (Britain and Ireland); a species (Atlantopsocus adustus) characteristic of Madeira and the Canary Islands has now been discovered in Cornwall [4]. Awareness of the impact of a warmer climate has grown in recent years, along with concerns about its influence on the appearance of new species in historic collections. Their discovery may also arise from greater
(C) Chemistry Central 
movement of objects between collections, which transports insects between properties. There is also the potential impact of changes in food [5], wider use of natural fabrics, and a more cautious approach to the use of pesticides [2].

The work presented here uses simple descriptive statistics to explore more than a decade of insect trapping data from properties managed by English Heritage (EH), which was used to get a greater understanding of the distribution and changes in insects populations. Although this paper refers to insects, some of the catch identifies not only insects, so for example woodlice, which are isopods belonging to the crustacea, are frequently logged in large numbers on the traps. The colloquial use of the term bugs (formally Hemiptera) or the term arthropods might better describe the subject of this work, but in the end we have accepted the word "insect" even though it is slightly inaccurate, it seems to capture what most readers will search for in a title.

The research also considered environmental and indoor habitat changes as possible explanations for the insect populations that are observed. However, it takes a "black box" approach, treating the insects caught and the properties evaluated in statistical terms, which limits the interpretation. This should allow strategic analysis, but the results from more focussed research is the subject of subsequent work. Ultimately an improved understanding of these issues should contribute to Integrated Pest Management strategies, although previous assessments of catch have often been limited to the contents of a limited number of traps e.g. [6]. Additionally there is relatively little guidance for the interpretation of insect catches from historic properties e.g. [7]. This study will provide a background against which changes might be measured, especially in studies concerned with the possibility that change is driven by an increasingly warm English climate [3].

\section{Method}

The key data in this project is taken from the quarterly inspection of traps laid out in a subset of $\mathrm{EH}$ properties over a period of more than ten years. The traps consist of sticky museum traps [8] sometimes termed blunder traps as in Figure 1a), along with smaller numbers of "bat proof" traps, plastic floor traps (Figure 1b) with sticky inserts (used where there is a lot of dust and debris), and pheromone-containing traps for some moths [9]. In all of these traps, insects walk or fly onto the sticky surface and are thus trapped. Larvae fall or sometimes wriggle onto the traps. No specific permits were required for the invertebrate trapping and care was taken not to trap mammals where they were likely to wander onto traps. These studies did not involve endangered or protected species. At the end of each quarter

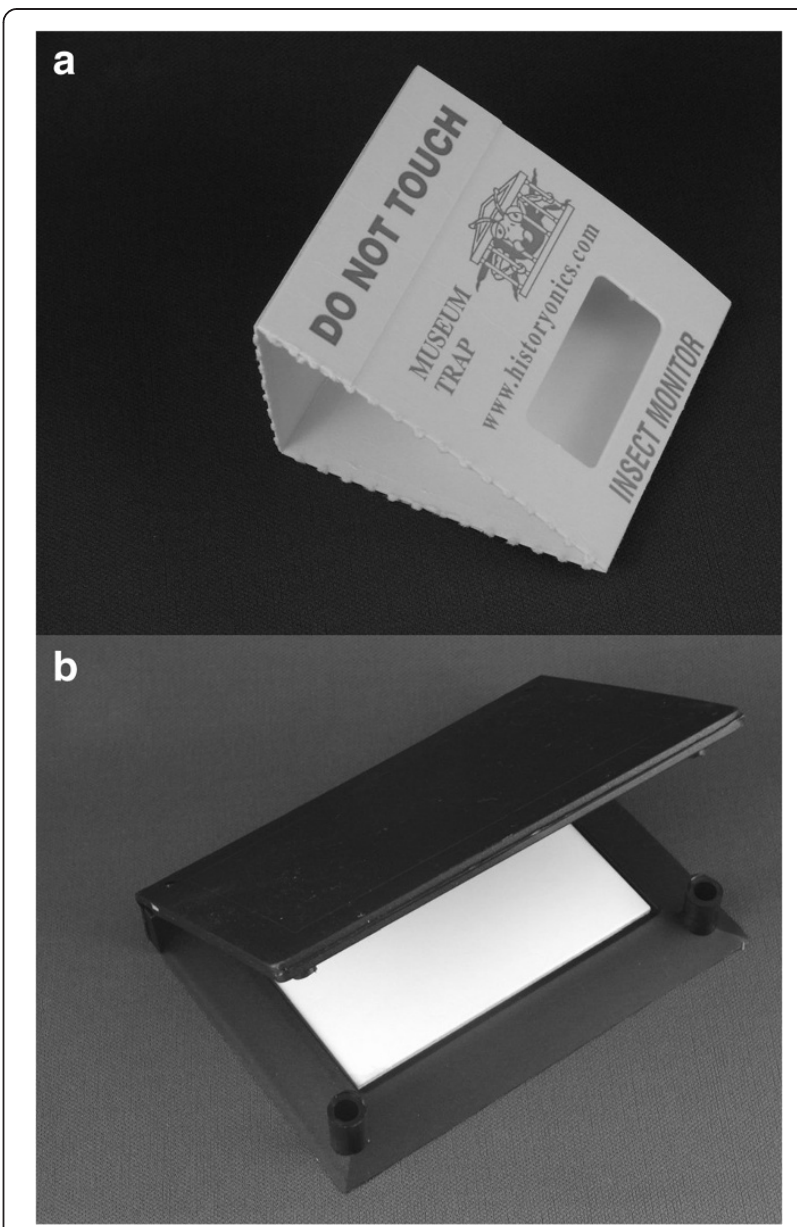

Figure 1 The standard blunder trap and "bat proof" trap. (a) The standard blunder trap $\sim 70 \mathrm{~mm} \times 90 \mathrm{~mm}$ typically used to capture the most of the insects discussed in this paper (b) The plastic "bat proof" trap which has a sticky cardboard replaceable insert. When closed the entry gap that is less than $15 \mathrm{~mm}$ prevents bats from coming into contact with the sticky surface. Photographs by permission of Robert Child.

the traps are collected, and the insects identified among a group of $20+$ species that characterise $\mathrm{EH}$ properties (Table 1). The insect counts were entered into the columns of standardised Excel spreadsheets where each row represented a site at a property. Insects were ordered in columns from left to right in order of the potential to cause damage to $\mathrm{EH}$ collections (high to low). The spreadsheets were designed only to capture data on 20 insect species or larvae of the species and woodlice, but did not categorise other insects, animals or objects caught in the traps. Other insects were at times noted in freeform comments; these included flies, ants, fungus beetles, various species of mites, black ground beetles, rove beetles and pseudo-scorpions. The Excel files were gathered centrally.

English Heritage territories, which have contributed data collected as part of management practice are shown 
Table 1 Insects allocated to types and total number of individual species found in traps in order of abundance; where a species is not defined, it is shown in parenthesis

\begin{tabular}{|c|c|c|c|}
\hline EH order & Common Name & Latin name & Found \\
\hline 21 & Booklice & Liposcelis bostrychophila & 65622 \\
\hline 22 & Silverfish & Lepisma saccharina & 23548 \\
\hline 23 & Woodlice & (Porcellio spp.) & 12163 \\
\hline 16 & Plaster beetle & Lathridiidae & 6351 \\
\hline 10 & Woolly bear ${ }^{(1)}$ & (Anthrenus spp.) & 5701 \\
\hline 9 & Varied carpet beetle ${ }^{(a)}$ & Anthrenus verbasci & 1137 \\
\hline 4 & Webbing clothes moth ${ }^{(a)}$ & Tineola bisselliella & 882 \\
\hline 1 & Brown house moth & Hofmannophila pseudospretella & 807 \\
\hline 13 & Two spot carpet or fur beetle ${ }^{(l)}$ & Attagenus pellio & 622 \\
\hline 17 & Wood weevil & Pentarthrum and Euophryum & 540 \\
\hline 3 & Case bearing clothes moth ${ }^{(1)}$ & Tinea pellionella & 532 \\
\hline 14 & Biscuit beetle & Stegobium paniceum & 508 \\
\hline 8 & Furniture beetle & Anobium punctatum & 504 \\
\hline 2 & Case bearing clothes moth ${ }^{(a)}$ & Tinea pellionella & 473 \\
\hline 24 & Mealworm & Tenebrio molitor & 419 \\
\hline 6 & White shouldered house moth & Endrosis sarcitrella & 405 \\
\hline 7 & Deathwatch beetle & Xestobium rufovillosum & 261 \\
\hline 12 & Two spot carpet or fur beetle ${ }^{(a)}$ & Attagenus pellio & 229 \\
\hline 5 & Webbing clothes moth ${ }^{(1)}$ & Tineola bisselliella & 195 \\
\hline 19 & Golden spider beetle & Niptus hololeucus & 194 \\
\hline 20 & White marked spider beetle & Ptinus fur & 184 \\
\hline 11 & Guernsey Carpet beetle & Anthrenus sarnicus & 108 \\
\hline 18 & Australian spider beetle & Ptinus tectus & 67 \\
\hline 15 & Hide or leather beetle & (Dermestes spp.) & 63 \\
\hline 25 & Other & & 21806 \\
\hline
\end{tabular}

English Heritage lists the insects in the order noted by the numbers as a rough assignment of their importance. Note: (a) adults (I) larvae.

in Figure 2. These include historic houses, tunnels and castles, and stores. We can see that some properties have relatively limited records, although a number of key sites have fairly continuous data spanning more than a decade (Table 2). London and the Southeast have the largest amount of data, but these territories also have the highest density of properties managed by EH housing vulnerable collections. Although useful, the chart does not indicate the number of traps set out in each of the properties, as it would encompass thousands of individual trapping locations. At individual properties this ranges from just four at the Medieval Merchants House in Southampton to sixty-eight traps at Brodsworth Hall in Yorkshire. Additionally, rooms where traps were placed within the properties were subject to change over the years, and position of the traps within the rooms could also change.

Although some 32000 traps were placed, a substantial proportion were lost or damaged. More than 500 traps were listed as missing, damaged or unreadable, and so were removed from the dataset before analysis. This prevented confusion with traps which were examined, but free of any of the listed insects (Table 1). Some 54\% of the traps contained insects that were categorised and about $10 \%$ of the traps had other observations such as trapped flies, presence of predators, frass etc. Table 1 shows booklice, silverfish and woodlice to be the most abundant. The woolly bear larvae (typically the larva of the varied carpet beetle, Anthrenus verbasci and the Guernsey carpet beetle, Anthrenus sarnicus) and clothes moths were also found frequently.

Among the traps placed out there were more than 550 that contained pheromones to attract either the webbing clothes moth (Tineola bisselliella) or the case bearing clothes moth (Tinea pellionella). There are observations from more than 29600 of the simpler sticky traps, and it is these that form the basis of much of the discussion here. The data is difficult to interpret and gain an overall 


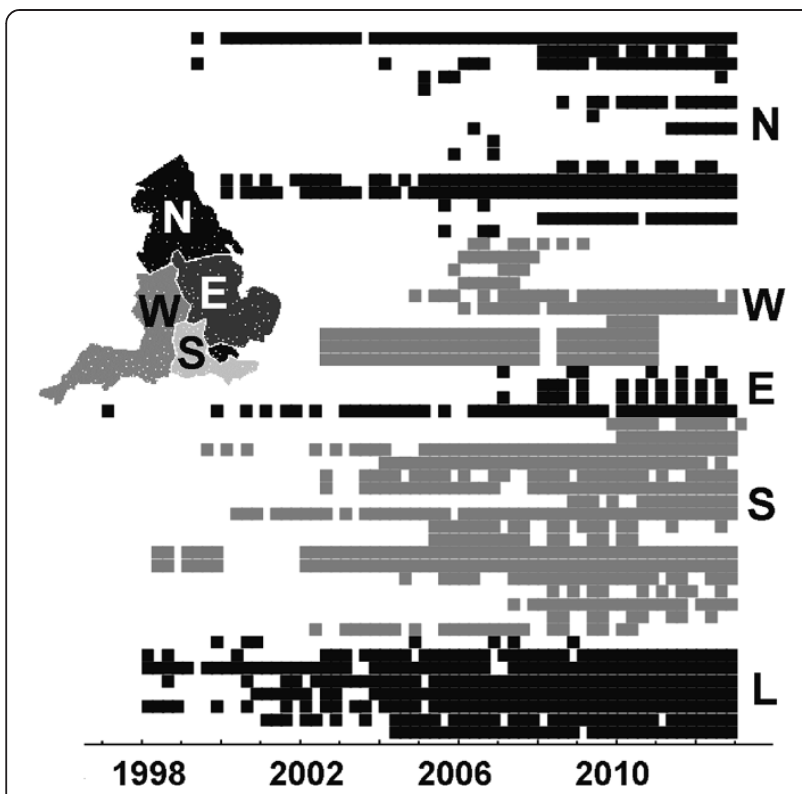

Figure 2 Available data from London (L), Southeast (S), East (E), West (W) and North (N) EH territories. London has been separated from the Southeast as there is such extensive data from London. Shaded areas show quarters where data is available, each row representing a property. The territories are shown in the map to the left, labelled except for London, which is the smallest area in dark shading.

Table 2 List of key properties with sufficient sample data

\begin{tabular}{lllrcc}
\hline No. & Name & Territory & Traps & Maximum & Quarters \\
\hline 42 & Apsley House & London & 1079 & 35 & 32 \\
149 & Chiswick House & London & 885 & 52 & 39 \\
200 & Down House & London & 1663 & 43 & 47 \\
217 & Eltham Palace & London & 1444 & 35 & 44 \\
361 & Kenwood House & London & 1330 & 36 & 45 \\
434 & Marble Hill House & London & 1258 & 26 & 52 \\
532 & Ranger's House & London & 1444 & 37 & 43 \\
474 & Osborne House & Southeast & 1877 & 42 & 50 \\
641 & Walmer Castle & Southeast & 1403 & 34 & 47 \\
983 & Annexe Tunnels & Southeast & 826 & 38 & 35 \\
984 & Casemate Tunnels & Southeast & 514 & 16 & 38 \\
34 & Audley End & East & 2532 & 72 & 42 \\
45 & Atcham Store 26 & West & 551 & 17 & 33 \\
52 & Atcham Store 30 & West & 387 & 16 & 33 \\
47 & Atcham Store 31 & West & 177 & 8 & 33 \\
351 & Kenilworth Castle & West & 359 & 16 & 27 \\
109 & Fulford Store & North & 1307 & 36 & 42 \\
801 & Brodsworth Hall & North & 3403 & 71 & 51 \\
\hline
\end{tabular}

Properties with data sufficient for more detailed study, giving the EH property number, name and territory, along with the total number of blunder traps retrieved, the maximum number placed out in a quarter and the number of yearly quarters available for analysis. sense of distribution or change. On the simplest level it exists on almost 1500 individual spreadsheets collected for management purposes over more than ten years. The data contained on the individual spreadsheets were transformed to a single ASCII file for each territory, which could then be read by a wide range of software.

The use of MS Access, Oracle, other SQL databases, or a single spreadsheet to record and store the source data would be efficient approaches, and would eliminate the need to translate the data in this way. Much of the initial processing was done with the simple UNIX script processing language awk, which had the advantage of supporting regular expressions that could interpret property and insect names or alphabetic codes that were entered into fields of the files. The data is unevenly distributed across the territories and through time. It was also important to consider the extent to which insects might have been misidentified or incorrectly entered into columns of the database, although this seems to smaller than other errors, such as miscounting when the catch becomes large. Entry of numbers into incorrect columns can arise at a number of stages from typing the sheets through to the conversion into ASCII code, also complicated by changes to the number and descriptions of the columns and rows used in the sheets over time. The entry of spurious comments which can push numbers into different columns has been a special problem, so considerable effort went into re-inspection of the original sheets to eliminate these incorrect entries. Future trap reporting would benefit from standard methods for recording and storing large amounts of data, consistent terminology, and more stringent controls on the content of cells.

Applying statistical operations to insect catch can be troublesome because just a small integer number is typically recorded per trap. The distribution is highly skewed. Nevertheless we have retained the mean as a measure of central tendency, as the median and mode were often zero for many insects. We do not mark standard deviation in the figures as this can also be misleading for highly skewed distributions. In the cases where we need to express correlation we adopt the Kendall $\tau$ rank correlation coefficient along with its two-sided $p$-value as an estimate of significance using the online Wessa.net web-enabled applications (http:// www.wessa.net/). Traditional statistical tests of hypothesis such as the parametric Student's $t$-test, were avoided in favour of the non-parametric Mann-Whitney $U$ test in Wessa.net at the section from Statistics Education at Aston University (http://www.wessa.net/aston_university.wasp). The slopes of lines for the time series analysis was taken as a Theil-Sen slope and using the tool provided by Single Case Research (http://www. 
singlecaseresearch.org/calculators/theil-sen). The TheilSen slope is distribution free, and is efficient with non-normal and skewed data. It can be thought of as the median slope. The Chi-squared test was used, but adopted with caution as it was likely to be affected by the large and sometimes uneven sample sizes.

\section{Results and discussion}

An initial inspection showed frequent occurrence of numbers such as 20, 30, 100 when the catch became large, possibly due to the difficulty in counting very small insects such as booklice, or when a trap has become saturated with insects. This is likely to overestimate the catch of abundant insects in traps that have become saturated, an error which is most pronounced with booklice. However, these are not the most harmful of insect pests, so it is not likely to lead to an overreaction in terms of pest management.

\section{Geographical spread of catch}

Insects are trapped with different frequencies in the different territories. Figure 3 shows the regional spread of insects. Our analysis of the data has to be normalised for changes in the number of traps, so results are often expressed as a catch rate, in terms of the number of insects caught per trap. The term catch rate has been adopted from fisheries research, where it is determined as the number of fish caught for a given effort, such as number of hooks, nets or traps e.g. [10].

In our study the catch rate is highest in London and the Southeast (Figure 3a), and the percentage of traps that had an identified insect present (\% occupancy) follows a similar pattern (Figure 3b), although London dominates with the largest prevalence of occupied traps. London properties have high visitor flow and are open year round, so there is an elevated potential to introduce pests or foodstuff. The properties also exchange and loan collections more frequently than elsewhere. Some of the London houses have experienced problems with damp, and it is always an issue to maintain guttering, chimneys and fireplaces. These provide routes for access, but also if animals, mammals or birds are trapped and die, the carcasses attract insects. Birds' nests are a further source of insects. Housekeeping is often stretched in the London properties, and there is greater staff turnover. There is clearly a range of characteristics of the properties that offers possible explanations for their high insect catches.

The catch rate for some individual species is shown in Figures 3c-3h, and here we see apparent differences in the regional distribution of insects $(p<0.001$ for each figure, Chi-squared test DoF $=4$ ). London for example shows a high frequency of silverfish, woolly bear larvae and webbing clothes moths compared with other
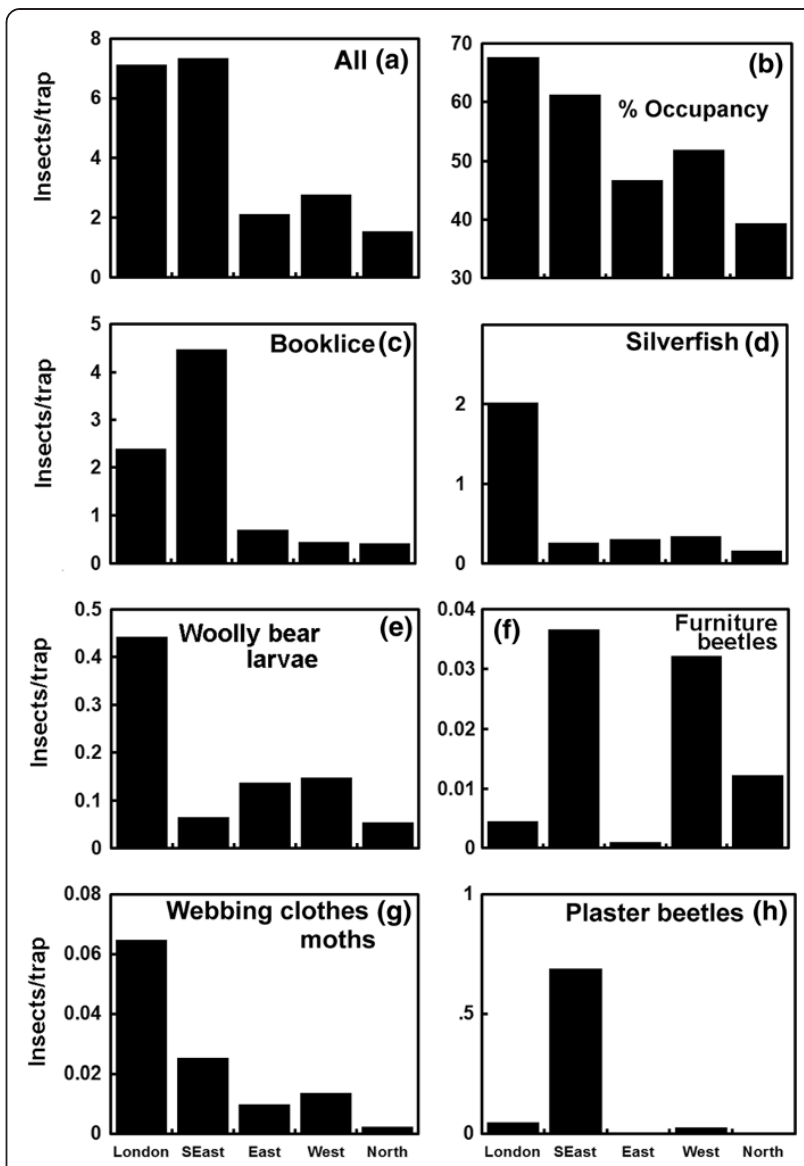

Figure 3 Average catch rate across the territories. (a) The average catch rate for all identified insects in each of the territories. (b) Percentage occupancy of traps, i.e. traps with one or more insects in each of the territories. Average catch rate for (c) booklice, (d) silverfish, (e) woolly bear larvae, (f) furniture beetles, (g) webbing clothes moths and (h) and plaster beetles in each territory.

territories. A high frequency of furniture beetles is notable in the Southeast and West, but to some extent these are driven by its prevalence in the Annexe and Casemate Tunnels (in the Southeast) and Atcham stores (under closure) in the West. In general the beetle is only found at $1.7 \%$ occupancy in relation to the number of traps throughout the record, although at just over 3\% the Southeast and the West $(p=0.02$, Mann-Whitney $U$ test), but in the Tunnels and Atcham stores it is at $5.1 \%$ and $5.2 \%$ respectively (significant difference between these sites and the Southeast and the West territories; $p=0.04$, Mann-Whitney $U$ test). The wood weevils (Pentarthrum and Euophryum), show similar patterns to the furniture beetle, with highest catch rates in the southeast (0.053) and the west (0.028). Plaster beetles (Lathridiidae), as discussed below, are frequent in the Southeast. 


\section{Variation between properties}

Catch varies a great deal between individual properties. Annexe and Casemate Tunnels in the Southeast show high average catch rate for booklice (15.1 and 11.8 per trap; significant difference between these sites and the entire data set: $\mathrm{p}<0.001$, Mann-Whitney $U$ test), but few silverfish. It is possible that the silverfish do not like the alkaline conditions in the tunnels, which are cut into fine-grained soft, white Dover chalk. Silverfish are frequent at Eltham Palace in London, which can be quite damp (8.1 per trap; significantly different from the complete London data: $\mathrm{p}<0.001$, Mann-Whitney $U$ test). The insect is trapped at almost five times the rate of any other of the key sites. Woodlice are especially abundant at Walmer Castle, but also found at high frequency in the Tunnels and Atcham stores. Woolly bear larvae are notably abundant in the London properties; more abundant in the seven houses than at any other of the key properties discussed in this paper. They are most frequent at Apsley House with 0.70 per trap.

A high relative abundance of plaster beetles is found in Annexe Tunnels (6.0 per trap) and at Casemate Tunnels (0.45 per trap), but are less frequent elsewhere $(\mathrm{p}<0.001$, Mann-Whitney $U$ test). Plaster beetles feed on mould so as the Tunnels are damp, the environment may be suitable for the growth of this food source. As mentioned before the furniture beetle (Anobium punctatum) is frequent in Atcham Stores, especially at Atcham Store No. 31 (0.13 per trap) and the Tunnels of the Southeast Territory. Although found in five of the key London properties, the furniture beetle is not caught at high frequency in the capital.

The descriptions outlined in the paragraph above suggest such great variability on a property-by-property basis that it becomes hard to draw clear conclusions. There seems little relationship between the patterns of species catch observed in the properties. Of course some insects such as booklice are the most prevalent insect at almost every site, but the catch rate varies enormously.

London properties are more constant in terms of the number of traps laid over the years and the nature of the properties, so seemed possible to test whether the distributions of trapped insects show different statistics. The low catch of many insects restricted the chi-square test to a contingency table of the most abundant insects: woolly bears, booklice, silverfish and woodlice. The test suggested that counts of these insects from the seven London properties do not follow a consistent distribution $(p=0.001$, Chi-squared test, DoF $=18)$. This lends support to the individualistic nature of the properties with respect to the insects trapped.

\section{Trends}

There is a general view that insects have been on the increase in properties $[2,11]$. Some examples of the changes over time are shown in Figure 4; most notably that the average catch of booklice over all properties is seen to increase over the period 2000-2012 in Figure 4a (Theil-Sen slope $=0.11 ; p=0.02$, Kendall $\tau$ ). There are hints in Figure $4 \mathrm{~b}$ that the average catch of woolly bear larvae might decrease when averaged across all sites, although the trend is hardly convincing (Theil-Sen slope $=0.05 ; p=0.18$, Kendall $\tau$ ). The problem with these two examples is that they could be affected by changes in the location of traps over time. An attempt to control for this is illustrated in Figure 4c, which shows the trends in woolly bear larvae at Apsley House (open squares) and Down House (black diamonds) in London, where there is a high abundance of these larvae. The plotted values don't reveal either similar or convincing trends (respectively: Theil-Sen slope $=0.03$;

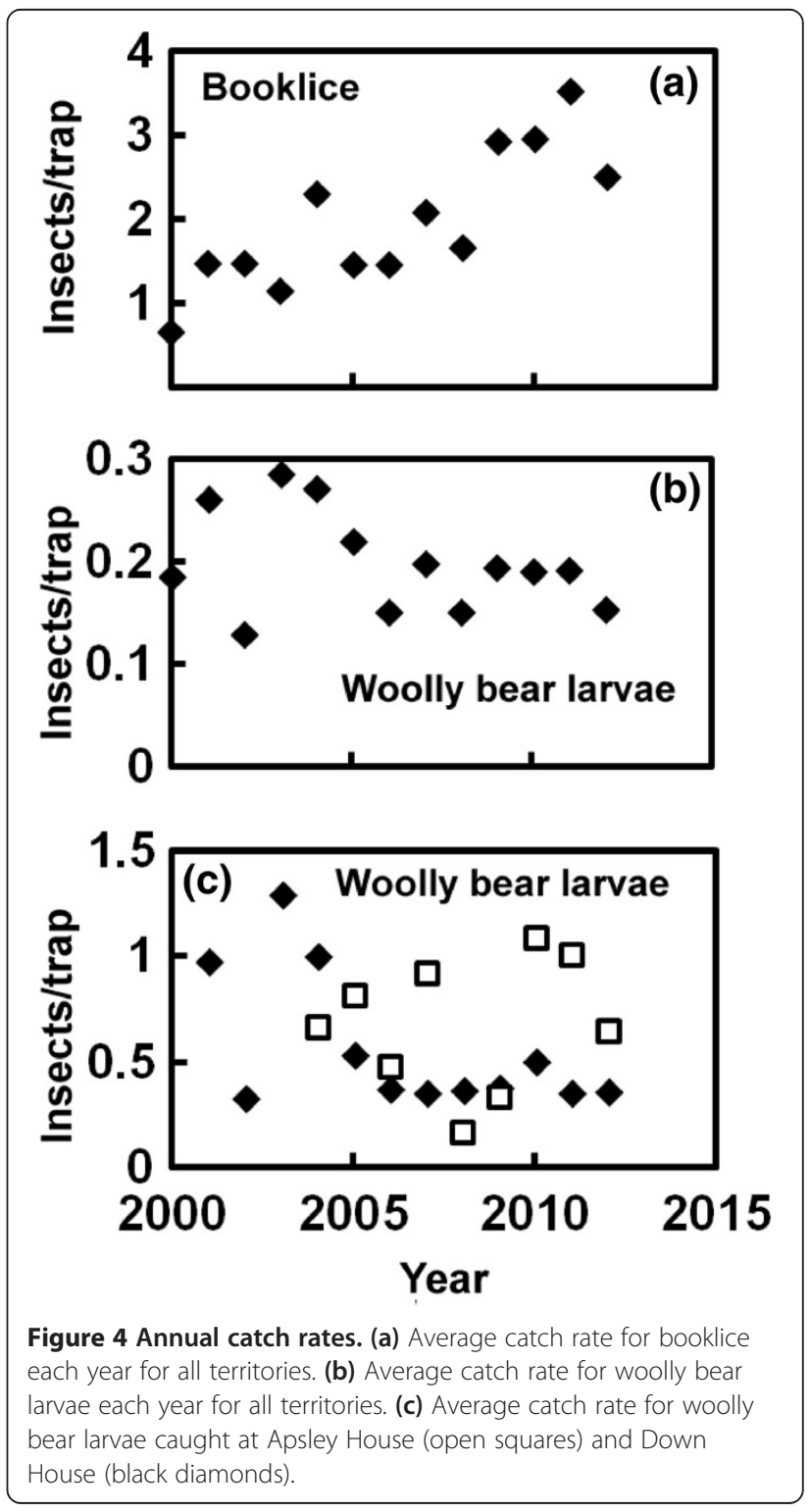


$p=0.68$, Kendall $\tau$ and Theil-Sen slope $=-0.003 ; p=$ 0.68 , Kendall $\tau$ ). Despite the difficulty in establishing trends, it will form an important part of future studies.

Nevertheless, we can imagine that over successive years the environment and climatic conditions in the London properties, although showing no monotonic trend might be rather similar. This would lead to an expectation that these properties could show similar fluctuations in insect populations year-by-year. The degree of correlation was explored using a correlation matrix for catch rate for all insects. The correlation coefficients in this matrix were determined using the Kendall $\tau$ rank correlation, rather than the normal Pearson correlation coefficient, as the former is less sensitive to the skewed distribution likely to arise from the high numbers that come with infestations. The correlation between the catch rate for all insects each year are shown in the upper right half of Figure 5. In general correlations were low with only two (asterisked in large italic font) exceeding 95\% level of confidence. The overall numbers are likely to be dominated by booklice or silverfish, which are by far the most numerous insects. Correlations with the abundant woolly bear larvae (displayed in the lower left half of Figure 5) revealed a similar low level of association, and one of the two that were significant was negative.

\section{Seasonal variation of catch}

The seasonal distribution of catch rate from all traps is shown in Figure 6a $(\mathrm{p}<0.001$ for each figure, Chi-squared test: $\mathrm{DoF}=3$ ). Not surprisingly it is the summer and then spring with the highest catches, although there is a reasonable number of insects caught in all quarters. The seasonal distribution of booklice and silverfish shown in Figures $6 \mathrm{~b}$ and $6 \mathrm{c}$ follow a similar pattern. The webbing clothes moth seen in Figure 6d, shows a high catch rate in the autumn. Lower proportions are found in traps from the winter and spring, with the seasonal profile shifted slightly later in the year for the adult (Figure 6f) compared to the larva (Figure 6e).

\section{Statistics of infestation}

The above sections show that trapped insects are not evenly distributed across the properties. However, neither are they randomly distributed, as seen with the predominance of certain insects at given properties. The underlying statistical distribution of insects also reflects

\begin{tabular}{|c|c|c|c|c|c|c|c|}
\hline & & & & & \multicolumn{3}{|c|}{ All insects } \\
\hline & $\mathbf{R}$ & F & $\mathbf{E}$ & K & $\mathbf{D}$ & $\mathbf{A}$ & M \\
\hline $\mathbf{R}$ & & -.13 & .36 & -.20 & .23 & $.56^{*}$ & -.10 \\
\hline & .13 & & -.18 & .18 & -.33 & -.22 & $.48^{*}$ \\
\hline$E$ & $.48^{*}$ & .27 & & -.21 & .33 & .00 & .18 \\
\hline & .09 & -.15 & -.03 & & -.12 & -.05 & -.03 \\
\hline & .33 & .36 & .03 & .24 & & $.55^{*}$ & -.37 \\
\hline & .06 & -.16 & .39 & -.05 & -.05 & & -.38 \\
\hline & -.12 & $.54^{*}$ & -.03 & .12 & .05 & .39 & \\
\hline $\mathbf{W}$ & $y$ & beá & 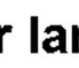 & ae & & & \\
\hline $\begin{array}{l}\text { Figure } \\
\text { for the } \\
\text { The ast } \\
\text { level of } \\
\text { correlat } \\
\text { larvae a } \\
\text { Chiswic } \\
\text { House; }\end{array}$ & $\begin{array}{l}\text { Upper } \\
\text { nnual a } \\
\text { isked bol } \\
\text { onfidenc } \\
\text { n coeffic } \\
\text { various } \\
\text { House; } \\
\text { Apsley }\end{array}$ & $\begin{array}{l}\text { right, th } \\
\text { verage c } \\
\text { Id italic fi } \\
\text { ce. The lo } \\
\text { ients for } \\
\text {-ondon } p \\
\text { E. Eltham } \\
\text { House; } M\end{array}$ & $\begin{array}{l}\text { ce Kenc } \\
\text { catch } r \\
\text { figures } \\
\text { ower lef } \\
\text { annua } \\
\text { propert } \\
\text { Palace } \\
\text { M, Marb }\end{array}$ & $\begin{array}{l}\text { all } \boldsymbol{\tau} \text { ran } \\
\text { te at va } \\
\text { enote } \\
\text { half dis } \\
\text { average } \\
\text { s. Note: } \\
\text { K, Kenw } \\
\text { Hill Ho }\end{array}$ & $\begin{array}{l}\mathbf{k} \text { correl } \\
\text { rious Lo } \\
\text { lationsh } \\
\text { plays the } \\
\text { catch ra } \\
\mathrm{R} \text {, Rang } \\
\text { bod Hou } \\
\text { use. }\end{array}$ & $\begin{array}{l}\text { tion co } \\
\text { ndon pr } \\
\text { os excee } \\
\text { Kendall } \\
\text { e for wo } \\
\text { r's Hous } \\
\text { se; D, Do }\end{array}$ & $\begin{array}{l}\text { efficients } \\
\text { roperties. } \\
\text { ding } 95 \% \\
\tau \text { rank } \\
\text { olly bear } \\
\text { e; C, } \\
\text { whn }\end{array}$ \\
\hline
\end{tabular}
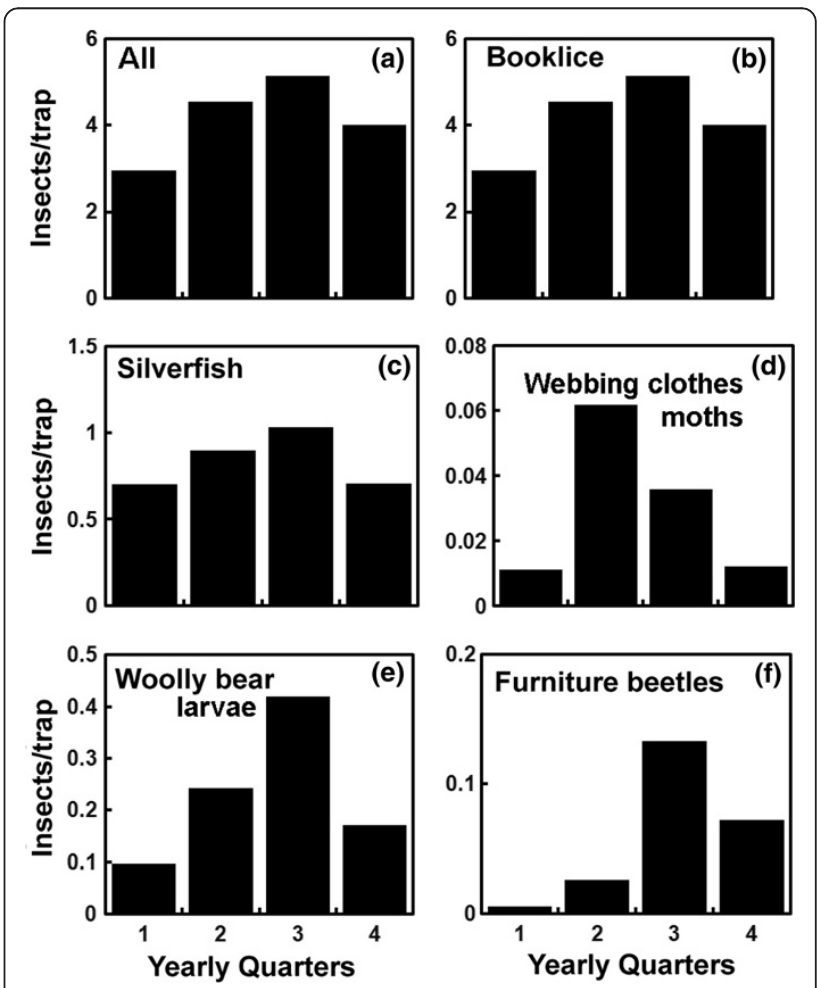

Figure 6 Seasonal catch rates. (a) Average seasonal catch rate for all insects shown for each quarter of the year. Average seasonal catch rate for (b) booklice, (c) silverfish, (d) webbing clothes moths, (e) woolly bear larvae and (f) furniture beetles for each quarter of the year. 
this non-random nature. If the insects were distributed randomly among the traps, there would be an expectation that they follow a Poisson distribution.

$$
I_{k}=T \lambda^{k} \exp (-\lambda) / k !
$$

where $I_{k}$ is the number of traps with $\mathrm{k}$ insects, T is the number of traps and $\lambda$ is the average number of insects caught per trap.

Looking at the overall data from all the traps; only one insect was found in $14.6 \%$ of the traps, $8.9 \%$ had two insects, while $6.2 \%$ and $4.2 \%$ had three and four insects respectively. Some traps had as many as two hundred insects (e.g. booklice). On average 4.13 insects are found per trap, which leads to the expectation shown by the continuous line in Figure 7a. This is quite different from the observed values (squares); there are too many traps with no insects or with very large numbers of insects to meet the requirements of a random distribution among the traps.

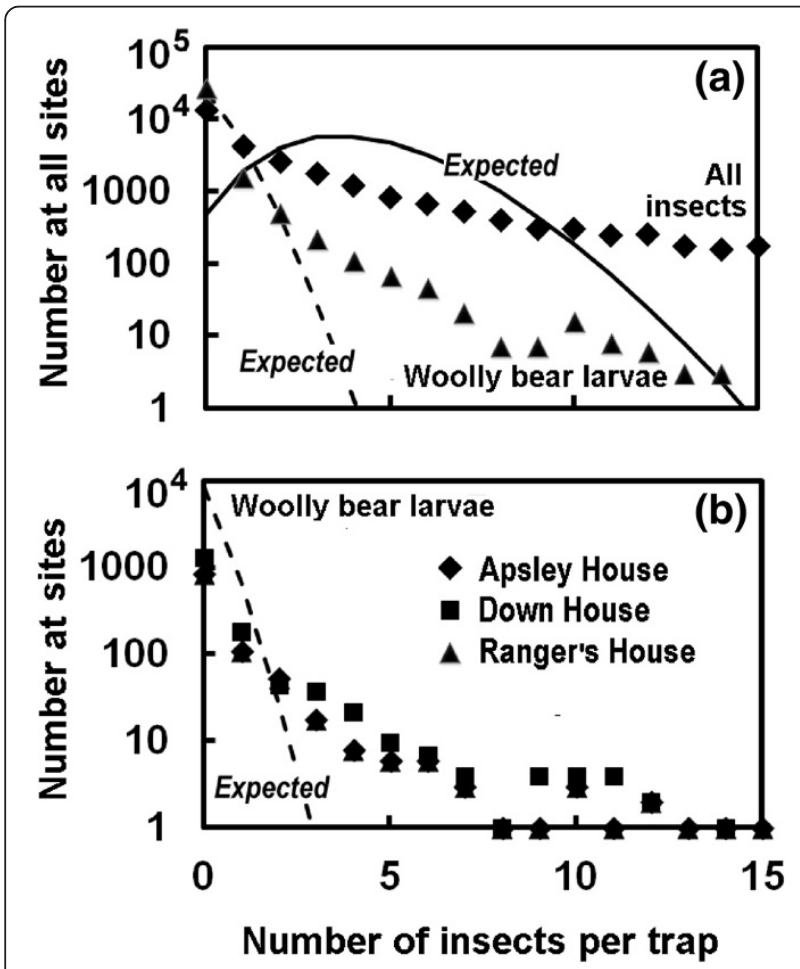

Figure 7 Total number of insects collected as a function of the number in individual traps. (a) The total number of insects collected in traps (displayed logarithmically) as a function of the number found present in the trap (range displayed 0-15) for all insects (diamonds) and for woolly bear larvae (triangles) in all territories. The lines show the expectation in terms of a Poisson distribution for all insects (solid line) and woolly bear larvae (dotted). (b) The total number of woolly bear larvae collected (displayed logarithmically) in traps at Ranger's House, Down House and Apsley House as a function of the number found present in the trap. The dotted line shows the expectation in terms of a Poisson distribution.
An analysis of the frequency distribution of the catch of woolly bears is displayed as triangles in Figure 7a. Although their abundance is very much less, with only some 4000 caught in total, reflecting an average of 0.19 larvae per trap, the number of multiple catches on the same trap is much higher than expected (shown as a dotted line) on the basis of a Poisson distribution.

This non-random distribution also repeated at the level of the individual property where unexpectedly high numbers of insects are to be found in individual traps. Figure 7b shows woolly bear catch at Ranger's House, Apsley House and Down House. Again the distribution does not follow that expected on the basis of a Poisson distribution (the dotted line shows the expectation for Ranger's House, but those for the other properties are similar). Once again there are too many traps with no insects, and too many that show infestations. This nonPoisson nature of the distribution reflects the potential for infestation. The drivers of infestation are not entirely clear, but for example recent work of Dalin et al. [12] has shown that infestations spread more rapidly in monoculture environments. Historic interiors might also represent are rather undifferentiated environment for insects.

\section{Statistics of species combinations}

Some of the traps that contained insects contained more than one specie. Table 3 shows that while most traps that were occupied had only a single species present, substantial proportions contained two or three species, and one trap had eight. The pattern tended to be repeated across the territories, although naturally where insects were generally at a lower frequency, such as in the North, the relative proportion of traps with multiple species declined more rapidly. The presence of dead insects on traps is likely to attract other insects that will feed on them and Anthrenus spp. and Attagenus spp. are notable in this respect. Both the adult and the larvae of these were more frequent on traps in the presence of

Table 3 The number of listed species found on individual traps from all territories

\begin{tabular}{lr}
\hline Species & Traps \\
\hline 0 & 13516 \\
1 & 9799 \\
2 & 4454 \\
3 & 1342 \\
4 & 268 \\
5 & 59 \\
6 & 8 \\
7 & 1 \\
8 & 1 \\
\hline
\end{tabular}


other insects than expected. Anthrenus spp. and Attagenus spp. adults were found in the presence of other species $68 \%$ of the time and for larvae this was much the same at $67 \%$. However, if the adult or larvae were distributed randomly this would be expected 53\% and $49 \%$ of the time. This increased prevalence was significant $(\mathrm{p}<0.001$, Chi-squared test $\mathrm{DoF}=1)$, although the test was not robust as the sample sizes were very different, 700-2800 where Anthrenus spp. and Attagenus spp. were present, and in excess of 26000 when they were absent. Woodlice are favoured by conditions of high humidity, so might frequently associate with other insects that prefer humid conditions.

The probability of one species being found with another can be easily estimated as the product of the two probabilities;

$$
p_{12}=p_{1} p_{2}
$$

where $p_{12}$ is the probability of the species present together and $p_{1}$ and $p_{2}$ are the probabilities of finding an species 1 and 2 on a trap. The relationship between the predicted and observed occurrence of species combinations is presented in Figure 8, which shows the number of traps with insect combinations found as a function of those expected on the basis of probability. Points occurring above the diagonal line suggests that there are a greater number found than expected.

In Figure 8a we can see that booklice and silverfish [i], booklice and woodlice [ii], booklice and woolly bears [iii], silverfish and woolly bears [iv] and booklice and plaster beetles $[\mathrm{v}$ ] were found together more often than expected. Silverfish and woodlice [vi] and woolly bears and woodlice [vii] (Figure $8 \mathrm{~b}$ ) lie close to the diagonal line and are thus near to the expected frequency. Although in smaller numbers, brown house moths (Hofmannophila pseudospretella) are found at higher than expected association with booklice [viii], and not surprisingly woolly bears are strongly associated with the varied carpet beetle [ix]- an adult form of the woolly bear. There is a lower than expected association between plaster beetles and silverfish [x] (Figure 8b).

\section{Pheromone and plastic floor traps}

Several hundred traps were laid that included pheromones as attractants for either the webbing clothes moth or less commonly the case bearing clothes moth. The largest number were placed in the key London properties after 2004. The catch rate was 2.67 moths per trap where pheromone was present, as expected e.g. [9] much greater than the 0.065 moths per trap caught when it was absent; a more than thirty-fold increase in catch rate $(\mathrm{p}<0.001$, Mann-Whitney $U$ test). Some $29 \%$ of the traps showed the presence of moths in the case of
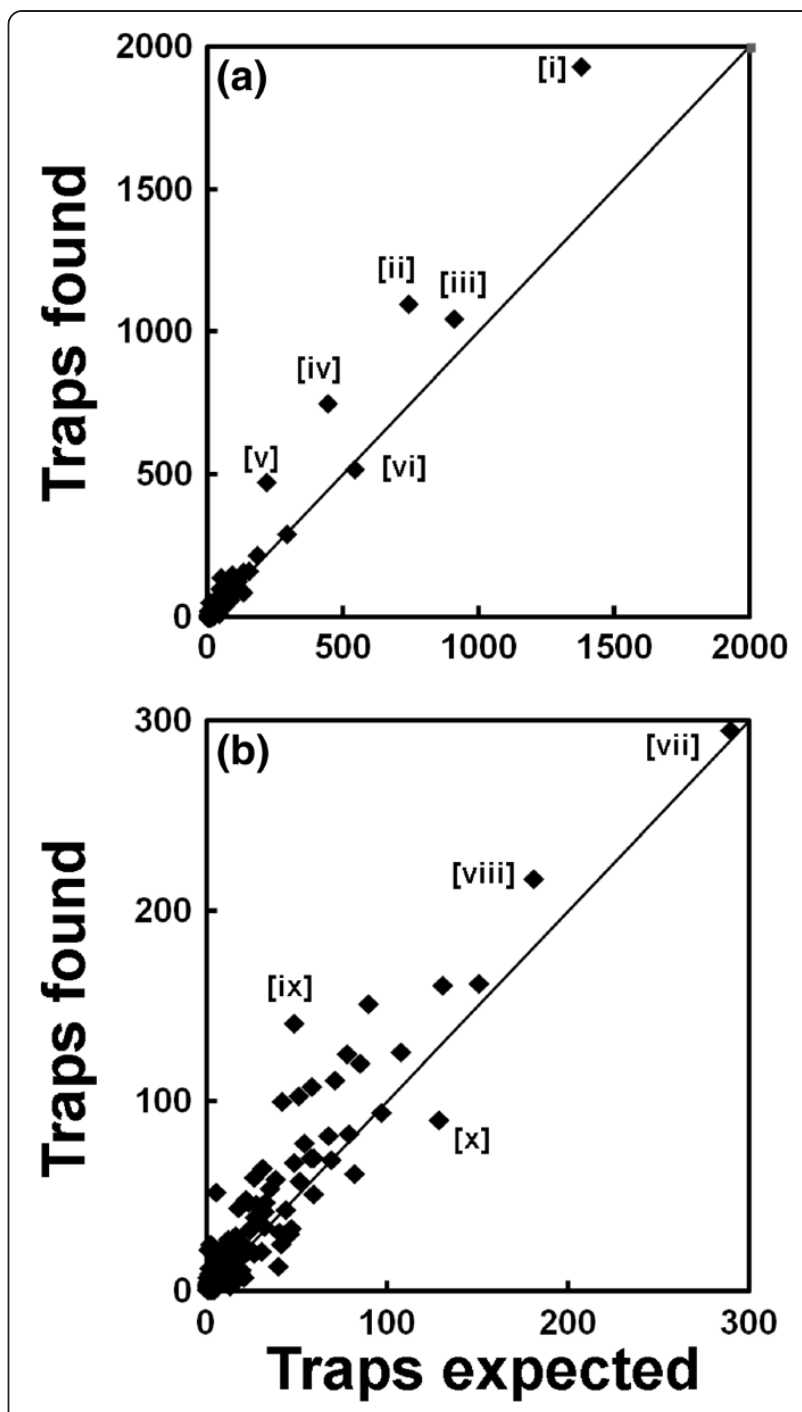

Figure 8 The number of traps, from all territories, with insect combinations found as a function of this expected on the basis of probability. The area above the diagonal line suggests a greater number of traps with combinations are found than expected. (a) Denotes particular combinations with bracketed Roman numerals: booklice and silverfish [i], booklice and woodlice [ii], booklice and woolly bears [iii], silverfish and woolly bears [iv] booklice and plaster beetles [v] silverfish and woodlice [vi]. (b) Denotes particular combinations, albeit at lower frequencies than in Figure 8a, with bracketed Roman numerals for combinations: woolly bears and woodlice [vii], brown house moths and booklice [viii] woolly bears and varied carpet beetle [ix] and plaster beetles and silverfish [x].

pheromone traps compared with $3.3 \%$ presence in the absence of the pheromone. This situation was repeated in the Southeast where the catch rate was 3.18 and 0.03 for the pheromone and non-pheromone traps $(\mathrm{p}<0.001$, Mann-Whitney $U$ test). Fewer pheromone traps were laid for the case bearing clothes moth and most of these were in the West. However, here the situation was much as expected with increases in the catch rate 0.97 with 
pheromones and 0.05 without ( $<<0.001$, Mann-Whitney $U$ test) and the occupancy (respectively $20 \%$ and $2.1 \%$ ).

There is a possibility that plastic floor traps (PFTs) designed to exclude bats or dust and debris, may also have lowered insect catch. The largest number (83) of these were used at Kenilworth Castle where the overall catch rate was lower ( $\mathrm{p}<0.07$, Mann-Whitney $U$ test) in PFTs, 0.65 compared with 2.49 for the 276 simple blunder traps. Taking a single species, the crustacean woodlouse showed a catch rate in the PFTs of 0.385 , compared to 0.511 for the blunder traps $(\mathrm{p}<0.04$, Mann-Whitney $U$ test). The catch in PFTs tends to be dominated by crawling insects and larger flying insects may be excluded, so these traps may be less than ideal [2] and may fail to give a representative distribution of all insect species. Even on the open blunder traps not all insects are caught with the same efficiency, so it is necessary to be cautious about the extent to which the insects trapped represent the abundance in properties $[13,14]$.

\section{Conclusion}

Certain insects such as booklice or silverfish are the most frequent in many properties. Not surprisingly the tunnels in the Southeast showed a high capture of booklice along with a relatively high frequency of plaster beetles. London properties were also notable in the frequency in which insects were trapped. Silverfish (Lepisma saccharina) had a very high catch rate at Eltham Palace. Woolly bear larvae were most frequent at Apsley House, but generally abundant on traps in all the London properties. The individualistic nature of insects present in properties was clear. London properties have high visitor flow and exchange of collections, are more difficult to maintain, and housekeeping is often stretched, which may be part of the explanation for the abundance of insects found there.

Trends over time were difficult to establish. The total rate of catch of booklice (Liposcelis bostrychophila) increased over time, but when we examined the seven houses in London, where there were rather similar approaches to sampling, there was no evidence of similar trends or correlations. Determining the relationship between changes in catch and climate or environmental factors requires more thorough analysis. The distribution of insects in traps did not follow the Poisson distribution, expected if insects were randomly distributed. This is evident from the occasional capture of large numbers of insects and hints at the importance of infestation. Some insects showed a tendency to be associated with other insects at a higher frequency than expected, but there were no especially obvious entomological reasons for this, apart from the occasional association of adults with their larvae. Webbing and case bearing clothes moths were more abundant in pheromone traps, confir- ming effective capture through the use of attractants. Traps that are covered to prevent dust or admission of bats may not give a true indication of the distribution of other insect species.

The trapping reported here provides clues for the management of pests in heritage properties. However, the individual character of pests at a given property means that the approach needs to be tailored to the needs of the property. It also suggests that although an insect might occur in low numbers in some periods, the possibility of infestation remains. The statistical analysis undertaken here did not identify any obvious drivers of high insect abundance in the traps. Future work will need to examine the trends in catch more carefully and ascertain the importance of environmental factors and food availability.

\section{Competing interests}

All the authors are associated with English Heritage, which manages the properties discussed.

DT and DL are employed full-time and PB and CTB work under a small short-term contract.

\section{Authors' contributions}

PB undertook the programming and statistical analysis, wrote the manuscript and constructed the figures. CTB organised the data and revised the manuscript. DT oversaw the project as a whole and reviewed the manuscript. DL gathered and collated the original data, reviewed the manuscript and gave insight into the entomology of the properties. All authors read and approved the final manuscript.

\section{Acknowledgements}

This work forms part of the English Heritage contract NHPP 2C2.301-6282. It would not have been possible without the efforts of staff who set the traps and recorded the results, sometimes for more than a decade. We would like to thank Helen Lloyd and other anonymous commentators for many useful observations on the first version of the MS, and to the referee who drew attention to Anthrenus spp. and Attagenus spp. being particularly attracted by dead insects.

\section{Author details}

${ }^{1}$ School of Environmental Sciences, University of East Anglia, Norwich NR4 7TJ, UK. ${ }^{2}$ Currently: School of Energy and Environment, City University of Hong Kong, Kowloon, Hong Kong. 'Write! Consultancy, 49 St Benedict's St, Norwich NR2 4PG, UK. ${ }^{4}$ English Heritage, Ranger's House, Chesterfield Walk, London SE10 8Q, UK.

Received: 30 June 2013 Accepted: 29 August 2013

Published: 8 November 2013

\section{References}

1. Pinniger DB: Pest management in museums archives and historic houses. London: Archetype Publications Ltd; 2001.

2. Pinniger DB: Ten years on - from vodka beetles to risk zones. In Integrated pest management for collections. Edited by Winsor $\mathrm{P}$, Pinniger $\mathrm{D}$, Bacon L, Child B, Harris K, Lauder D, Phippard J, Xavier-Rowe A. Swindon, UK: English Heritage; 2011:1-9.

3. Brimblecombe $P$, Lankester P: Long-term changes in climate and insect damage in historic houses. Stud Conserv 2013, 58:13-22.

4. Alexander KNA: Atlantopsocus adustus (Hagen) (Psoc.: Psocidae) new to Britain from East Cornwall. Entomol Rec 2007, 119:76.

5. Stengaard Hansen L, Akerlund M, Grontoft T, Rhyl-Svendsen M, Schmidt A, Bergh J, Vagn Jensen K: Future pest status of an insect pest in museums, attagenus smirnovi: distribution and food consumption in relation to climate change. J Cult Herit 2012, 13:22-27. 
6. Querner P, Simon S, Morelli M, Fürenkranz S: Insect pest management programmes and results from their application in two large museum collections in Berlin and Vienna, international biodeterioration \& biodegradation. J Int Biodeterioration Biodegradation 2012, 84:275-280.

7. Child R: The wider use and interpretation of insect monitoring traps. In Integrated pest management for collections. Edited by Winsor P, Pinniger D, Bacon L, Child B, Harris K, Lauder D, Phippard J, Xavier-Rowe A. Swindon, UK: English Heritage; 2011:66-70.

8. Child RE, Pinniger DB: Insect trapping in museums and historic houses. Stud Conserv 1994, 39(Supplement 2):129-131.

9. Cox PD, Pinniger DB, Mueller D: Monitoring populations of the webbing clothes moth, Tineola bisselliella, using pheromone lures. In Proceedings of the 2nd International Conference on Insect Pests in the Urban Environment, Edinburgh. Edited by Wildey KB, Robinson WH; 1996:541-545.

10. Stobart B, Alvarez-Barastegui D, Goñi R: Effect of habitat patchiness on the catch rates of a Mediterranean coastal bottom long-line fishery. Fish Res 2012, 129-130:110-118.

11. Xavier-Rowe A, Lauder D: Ten years of integrated pest management at English heritage. In Integrated pest management for collections. Edited by Winsor P, Pinniger D, Bacon L, Child B, Harris K, Lauder D, Phippard J, Xavier-Rowe A. Swindon, UK: English Heritage; 2011:10-15.

12. Dalin P, Kindvall O, Björkman C: Reduced population control of an insect pest in managed willow monocultures. PLOS 2009, 4:e5487.

13. Evans G: Driven to distraction by moths: IPM on the riverside museum project. In Integrated pest management for collections. Edited by Winsor P, Pinniger D, Bacon L, Child B, Harris K, Lauder D, Phippard J, Xavier-Rowe A. Swindon, UK: English Heritage; 2011:84-89.

14. Vaucheret $\mathrm{S}$, Leonard $\mathrm{L}$ : Dealing with an infestation of Reesa vespulae while preparing to move to new stores. In Integrated pest management for collections. Edited by Winsor P, Pinniger D, Bacon L, Child B, Harris K, Lauder D, Phippard J, Xavier-Rowe A. Swindon, UK: English Heritage; 2011:71-76.

doi:10.1186/2050-7445-1-34

Cite this article as: Brimblecombe et al:: Statistics of insect catch within historic properties. Heritage Science 2013 1:34

\section{Publish with ChemistryCentral and every scientist can read your work free of charge \\ "Open access provides opportunities to our colleagues in other parts of the globe, by allowing anyone to view the content free of charge." \\ W. Jeffery Hurst, The Hershey Company. \\ - available free of charge to the entire scientific community \\ - peer reviewed and published immediately upon acceptance \\ - cited in PubMed and archived on PubMed Central \\ - yours - you keep the copyright \\ Submit your manuscript here: \\ http://www.chemistrycentral.com/manuscript/<smiles>c1ccccc1</smiles> 